\title{
Development and validation of a competitive ELISA based on bacterium-original virus-like particles of serotype 0 foot-and-mouth disease virus for detecting serum antibodies
}

\author{
Xuhua Ran $^{1,2} \cdot$ Zhiyuan Yang $^{1,2} \cdot$ Manyuan Bai $^{1} \cdot$ Yun Zhang $^{1} \cdot$ Xiaobo Wen $^{2} \cdot$ Huichen Guo $^{1} \cdot$ Shiqi Sun ${ }^{1}$
}

Received: 26 November 2018 / Revised: 31 January 2019 / Accepted: 2 February 2019 / Published online: 19 February 2019

(C) Springer-Verlag GmbH Germany, part of Springer Nature 2019

\begin{abstract}
Foot-and-mouth disease (FMD) is a highly contagious disease that affects all susceptible cloven-hoofed animals, resulting in considerable economic losses to animal industries worldwide. Numerous categories of enzyme-linked immunosorbent assays (ELISA) have been developed and widely used to evaluate herd immunity. Manufacturing inactivated FMD virus (FMDV) as a diagnostic antigen requires a facility with a high level of biosafety, but this requirement raises concern on viral leakage. In our previous study, bacterium-original FMD virus-like particles (VLPs) resemble the authentic FMDV and induce protective immunity against homologous viral challenges, thereby demonstrating that they are sufficiently safe without limitations on biosafety facilities and easily prepared. Herein, we developed a competitive ELISA (cELISA) based on FMDV-VLPs as a diagnostic antigen to evaluate herd immunity. The criterion of this cELISA was determined by detecting panels of positive sera with different antibody titers and negative sera. The working parameter of cELISA was optimized, and samples with a percentage inhibition of $\geq 50 \%$ were considered positive. The specificity of cELISA to test 277 serum samples with various antibody titers was $100 \%$, and the sensitivity reached $96 \%$. The coincidence rates of cELISA with a VDPro® FMDV and a PrioCHECK ${ }^{\circledR}$ FMDV type O antibody ELISA kit were $97.8 \%$ and $98.2 \%$, respectively. Repeatability tests demonstrated that the coefficients of variation within and between runs were less than $7 \%$ and $14 \%$, respectively. Our data demonstrated that cELISA based on bacteriumoriginal VLPs had high specificity, sensitivity, and reproducibility. The cELISA could also be used for evaluating vaccination herd immunity effects, especially in developing countries.
\end{abstract}

Keywords Foot-and-mouth disease $\cdot$ Competitive ELISA $\cdot$ Virus-like particles $\cdot$ Herd immunity $\cdot$ Validation

\section{Introduction}

Foot-and-mouth disease (FMD) is a highly contagious and devastating viral disease affecting all susceptible clovenhoofed animals, and it causes considerable economic losses because of trade limitation and recovery efforts (Knight-Jones and Rushton 2013; Porphyre et al. 2018). FMD virus

Xuhua Ran and Zhiyuan Yang contributed equally to this work.

Shiqi Sun

shiqisun21@ hotmail.com

1 State Key Laboratory of Veterinary Etiological Biology, OIE/China national Foot-and-mouth Disease Reference Laboratory, Lanzhou Veterinary Research Institute, Chinese Academy of Agricultural Science, Xujiaping 1, Lanzhou 730046, Gansu, China

2 College of Animal Science \& Veterinary Medicine, Heilongiiang Bayi Agricultural University, Daqing 163319, Heilongjiang, China
(FMDV), its causative agent, is a single positive-stranded RNA virus encoding four structural proteins (VP1, VP2, VP3, and VP4) and 10 nonstructural proteins (NSPs; L, 2A$\mathrm{C}, 3 \mathrm{~A}-\mathrm{D}, 3 \mathrm{AB}$, and $3 \mathrm{ABC}$ ) and belonging to order Picornavirales, family Picornaviridae, and genus Aphthovirus (Han et al. 2015; Fry et al. 2005).

Large quantities of ELISA methods based on FMDV NSPs that differentiate infected from vaccinated animals (DIVA) have been extensively studied and validated, though the performance of some DIVA ELISAs, such as competitive ELISAs, blocking ELISAs, and capture ELISAs, based on selected NSPs or conserved epitopes on NSPs, varies in terms of FMD diagnosis by different serotype strains (Chung et al. 2018; Mahajan et al. 2015; Hosamani et al. 2015; Gao et al. 2012; Ma et al. 2011; Chen et al. 2011). The diagnosis depending on DIVA ELISAs may provide a valuable reference in FMD prevention and control. FMD control mainly involves vaccination with inactivated vaccines with selected serotypes 
and slaughter policies, particularly in FMD-free countries. However, some factors associated with economic status and social culture may compromise the implementation of the slaughter policy (Rawdon et al. 2018). Therefore, in some counties and local regions, vaccination with selected FMDV vaccine strains in accordance with circulating-field FMDV and in combination with the implementation of epidemiological surveillance remains the key strategy of FMD prevention and control (Ding et al. 2013; Roche et al. 2015). However, immunization with inactivated vaccines against FMDV results in humoral immunity with short-term effectiveness, thereby merely protecting animals from clinical diseases for approximately 4-6 months (Diaz-San Segundo et al. 2017). Thus, the estimation of herd immunity by regular seromonitoring is required for the determination of a vaccination protocol and the efficacy evaluation of experimental vaccines, indicating that this procedure is essential for the success of vaccination.

Although a virus neutralization test (VNT) is recommended by the Office International des Epizooties as a gold standard in a serological test for the detection of FMD antibodies in animals, VNT is time consuming, labor intensive, and sophisticated compared with those of alternative methods. A VNT for FMD diagnosis should be performed in a highlevel biosafety laboratory because viral leakage is the major concern for biosafety. Numerous ELISA formats, including indirect ELISAs and blocking-, competition-, or sandwichbased assays for seromonitoring, have been extensively developed (Feng et al. 2016; Basagoudanavar et al. 2013; Paiba et al. 2004; Chenard et al. 2003). However, the development of ELISA tests based on inactivated FMDV and referencepositive sera requires cell culture and animal immunization to prepare the included components, which need a high level of biosafety (Ferris et al. 1990). Therefore, recombinant proteins as diagnostic antigens in developing diagnostic assays may be a preferable alternative to overcome this limitation (Ko et al. 2009; Ko et al. 2012). For example, Oem et al. reported that recombinant FMDV pentamer-like structures are generated in a baculoviral expression system and utilized as diagnostic antigens in blocking ELISA (Oem et al. 2007). However, the preparation of recombinant proteins by using a baculoviral system is complicated and costly compared with manufacturing via a prokaryote expression system (Xiao et al. 2016). In our previous study, virus-like particles (VLPs) of FMDV Asia I serotype were generated by a SUMO fusion protein system in bacteria, demonstrating that VLPs resemble authentic FMDV particles (Guo et al. 2013). Vaccination with one dose of VLPs triggers a complete protection in guinea pigs, swine, and cattle against homologous FMDV challenge, indicating that FMDV-specific epitopes, either linear epitopes or conformational epitopes, can be well expressed and presented in VLPs originating from a bacterial expression system. Herein, we developed a competitive ELISA (cELISA) with type O FMD-VLPs as a coating antigen and evaluated its validation, sensitivity, and specificity to estimate herd immunization in domestic animals via commercially inactivated FMDV vaccines.

\section{Materials and methods}

\section{Serum samples}

A total of 311 serum samples were harvested from animals vaccinated with commercial serotype O FMD-inactivated vaccines, which included 122 sheep, 49 bovine, and 140 pig sera. Liquid-phase blocking (LPB) ELISA method revealed that 132 serum samples were confirmed to be positive against FMDV, whereas 179 samples were negative. The serum samples were obtained from the Key Laboratory of the Lanzhou Veterinary Research Institute of the Chinese Academy of Agricultural Sciences.

\section{Plasmid constructions}

The SUMO recombinant protein vector harboring FMDV serotype O VP0, VP1, or VP3 gene (Strain: O/BY/CHA/2010; GenBank accession number: JN998085.1) was constructed as described previously (Guo et al. 2013). In brief, VP0, VP1, and VP3 ORF were cloned into pSMK $\left(\operatorname{Kan}^{\mathrm{R}}\right)$, pSMA $\left(A m p^{R}\right)$, and pSMC $\left(\mathrm{Chl}^{\mathrm{R}}\right)$, respectively. Each of these three recombinant plasmids was confirmed by gene sequencing and assigned for pSMK-VP0, pSMA-VP1, and pSMC-VP3.

\section{Protein production and VLP quantification}

The three recombinant plasmids, namely pSMK-VP0, pSMA$\mathrm{VP1}$, and pSMC-VP3, were simultaneously transformed into Escherichia coli competent cells BL21 (DE3) (Stratagen, La Jolla, CA, USA), and recombinant bacteria co-expressing VP0, VP1, and VP3 were selected on an LB agar plate supplemented with ampicillin $(50 \mu \mathrm{g} / \mathrm{ml})$, kanamycin $(10 \mu \mathrm{g} / \mathrm{ml})$, and chloramphenicol $(30 \mu \mathrm{g} / \mathrm{ml})$. A single bacterial colony was inoculated into an LB broth supplemented with ampicillin $(50 \mu \mathrm{g} / \mathrm{ml})$, kanamycin $(10 \mu \mathrm{g} / \mathrm{ml})$, and chloramphenicol $(30 \mu \mathrm{g} / \mathrm{ml})$ and incubated at $37{ }^{\circ} \mathrm{C}$ with a shaker incubator. The bacterial inoculum was cooled to $16{ }^{\circ} \mathrm{C}$ when $\mathrm{OD}_{600}$ reached 0.7-0.9. The co-expression levels of recombinant proteins, namely VP0, VP1, and VP3, were induced with $0.5 \mathrm{mM}$ IPTG at $16{ }^{\circ} \mathrm{C}$ for $16 \mathrm{~h}$. SUMO-tagged recombinant proteins were purified as described before and analyzed through SDS-PAGE and western blot. SUMO-tag and Histag were removed using SUMO protease by incubation at $4{ }^{\circ} \mathrm{C}$ overnight, and the self-assembly of VLPs was simultaneously performed in the same reaction solution (Yin et al. 2010). The VLPs were purified using a sucrose gradient ultracentrifuge as previously described (Guo et al. 2013) and 
analyzed through SDS-PAGE and western blot. The quantity of the purified VLPs was determined using a Bradford protein assay kit in accordance with the manufacturer's instructions (ThermoFisher Scientific, Rockford, IL, USA), and the morphological characteristics of the FMD-VLPs were visualized with a transmission electron microscope as previously described (Guo et al. 2013).

\section{Animal immunization and serum purification}

Each of the three rabbits was intramuscularly injected with $200 \mu \mathrm{g}$ of purified VLPs with the aid of complete Freud's adjuvant and subjected to boost immunization with each amount of VLPs with incomplete Freud's adjuvant twice in 2-week intervals. The rabbits were bled 14 days after the final immunization, and sera against VLPs were harvested and stored at $-80{ }^{\circ} \mathrm{C}$ until use.

\section{Conjugation of rabbit hyperimmune sera with horseradish peroxidase}

The pooled rabbit IgG was precipitated with saturated ammonium sulfate at $4{ }^{\circ} \mathrm{C}$ for 30 min centrifuged at $3500 \mathrm{r} / \mathrm{min}$ at $4{ }^{\circ} \mathrm{C}$ for $30 \mathrm{~min}$. The pellet was resuspended using PBS (0.01 M, pH 7.2) to achieve the same volume of the original hyperimmune sera and precipitated with saturated ammonium sulfate thrice as described above. Salt was removed through dialysis against PBS (0.01 M, pH 7.2) at $4{ }^{\circ} \mathrm{C}$ overnight. Rabbit IgG was further purified using protein A Sepharose affinity column chromatography, and IgG was eluted with $0.1 \mathrm{M}$ citrate buffer ( $\mathrm{pH}$ 3.0), concentrated with centrifugal filter concentrators (Merck Millipore Ltd., Tullagreen, Carrigtwohill Co., Cork IRL), and analyzed through SDS-PAGE. The purified rabbit IgG was conjugated with horseradish peroxidase (HRP) by using a $\mathrm{NaIO}_{4}$-based assay (Minaeian et al. 2012). HRP-conjugated rabbit IgG was characterized through western blot and stored at $80{ }^{\circ} \mathrm{C}$ until use.

\section{Development of cELISA based on FMDV-VLPs and HRP-conjugated IgG}

An ELISA plate was coated with purified FMD-VLPs diluted in carbonate buffer solution $(0.05 \mathrm{M}, \mathrm{pH} 9.6)$ at varied concentrations $(0.5-1.0 \mu \mathrm{g} / \mathrm{ml})$ at $4{ }^{\circ} \mathrm{C}$ overnight and coated with each of the selected concentration of VLPs in duplicate. The ELISA plate was washed three or four times with $300 \mu$ of PBST (PBS with $0.1 \%$ Tween), then blocked with $1 \%$ bovine serum albumin (BSA) in distilled water at $37{ }^{\circ} \mathrm{C}$ for $60 \mathrm{~min}$, and washed three or four times with PBST. The FMD positive $(\mathrm{P})$ and negative $(\mathrm{N})$ sera were serially diluted in $50 \mu \mathrm{l}$ PBST
(1:2-1:32) in twofold and inoculated into each well of the ELISA plate with an equal volume of the diluted HRP-conjugated rabbit IgG (1:10000, 1:11000-1:20000). The plate was incubated at $37{ }^{\circ} \mathrm{C}$ for $60 \mathrm{~min}$ and washed three or four times with $300 \mu \mathrm{l}$ of PBST. Then, the ELISA plate was developed with $50 \mu$ of TMB substrate (Surmodics IVD Inc., USA) at $37{ }^{\circ} \mathrm{C}$ for $15 \mathrm{~min}$, and the reaction was terminated with $50 \mu \mathrm{l}$ of $2 \mathrm{M} \mathrm{H}_{2} \mathrm{SO}_{4}$. Absorbance at $450 \mathrm{~nm}$ was recorded, and reaction parameters and components, such as blocking buffer, were optimized on the basis of the ratio between the reading values of $\mathrm{P}$ and $\mathrm{N}$ sera. Percentage inhibition (PI) was calculated using the following formula:

$\mathrm{PI}=\frac{\mathrm{OD} \text { of standard negative sero-OD of each sample tested }}{\mathrm{OD} \text { of standard negative sero-OD of standard positive }} \times 100 \%$

\section{Determining the cutoff PI of cELISA}

In this procedure, 50 serum samples with various titers of positive antibodies against FMDV and 52 negative samples were confirmed with the prescribed methods, by which OIE recommends (OIE 2017). The serum samples were tested using cELISA developed in this study to determine the cutoff PI of cELISA that showed high sensitivity and specificity. The cutoff value was determined when the percentage of specificity and sensitivity reached the maximum value through receiver operating characteristic curve (ROC) analysis.

\section{Evaluating the performance of CELISA}

\section{Analytical sensitivity and specificity of cELISA}

After the cutoff criterion was determined, the sensitivity of cELISA was evaluated using panels of FMDV positive sera with various titers of antibodies. The specificity of cELISA was assessed using 135 sera of different origins, including the known porcine positive sera against serotype $\mathrm{O}$ or A FMDV, porcine circovirus type 2 , porcine pseudorabies virus, classical swine fever virus, porcine reproductive and respiratory syndrome virus, porcine parvovirus, or Japanese encephalitis virus.

\section{Repeatability test}

In this procedure, six serum samples were tested in triplicate to evaluate the repeatability of cELISA under optical parameters. The coefficients of variation $(\mathrm{CV})$ of inter- and intra-assay using cELISA were also calculated. 


\section{Correlation of cELISA with commercial ELISA}

For the assessment of the validation of cELISA through FMDVLPs and HRP-rabbit IgG, 277 serum samples with varied titers of positive antibodies against FMDV or negative antibodies were tested, and two commercial FMD test kits, namely a VDPro® FMDV Type O ELISA kit (Median Diagnostics lnc., Republic of Korea) and a PrioCHECK® FMDV type $\mathrm{O}$ antibody test kit (ThermoFisher Scientific, Rockford, IL, USA), were compared with cELISA on the basis of the optical parameters. The cut-off PI was also determined. The tests were performed in accordance with the manufacturers' manual.

\section{Results}

\section{Protein expression and examination}

The three recombinant plasmids harboring SUMO-tag were transformed into the same $E$. coli host cells subjected to selection pressure by supplementing with three kinds of antibiotics. The recombinant fusion proteins, VP0, VP1, and VP3, were simultaneously expressed under the induction of IPTG at $16{ }^{\circ} \mathrm{C}$ or $37{ }^{\circ} \mathrm{C}$. The co-expression of three SUMO-tagged fusion proteins was confirmed through SDS-PAGE (Fig. 1a) and western blot (Fig. 1b). The fusion recombinant proteins
Fig. 1 Analysis of three SUMOtagged recombinant proteins using SDS-PAGE and western blot (a). SDS-PAGE: M, protein molecular marker; lane 1 , prior to induction; lane 2, post induction. The SUMO-tagged recombinant proteins were induced as described in Materials and Methods. Identification of recombinant proteins with varied preparations using western blot(b). Lanes 1-2, recombinant proteins generated in varied preparations. Expression of recombinant proteins induced at $16^{\circ} \mathrm{C}$ and $37^{\circ} \mathrm{C}(\mathbf{c})$. Protein molecular marker $(\mathrm{M})$, supernatant (lane 1) and pellet (lane 2) of lysated recombinant E. coli incubated at $37^{\circ} \mathrm{C}$, supernatant (lane 3 ) and pellet (lane 4) of lysated recombinant E. coli incubated at $16^{\circ} \mathrm{C}$; and supernatant (lane 5) and pellet (lane 6) of lysated recombinant E. coli prior to induction
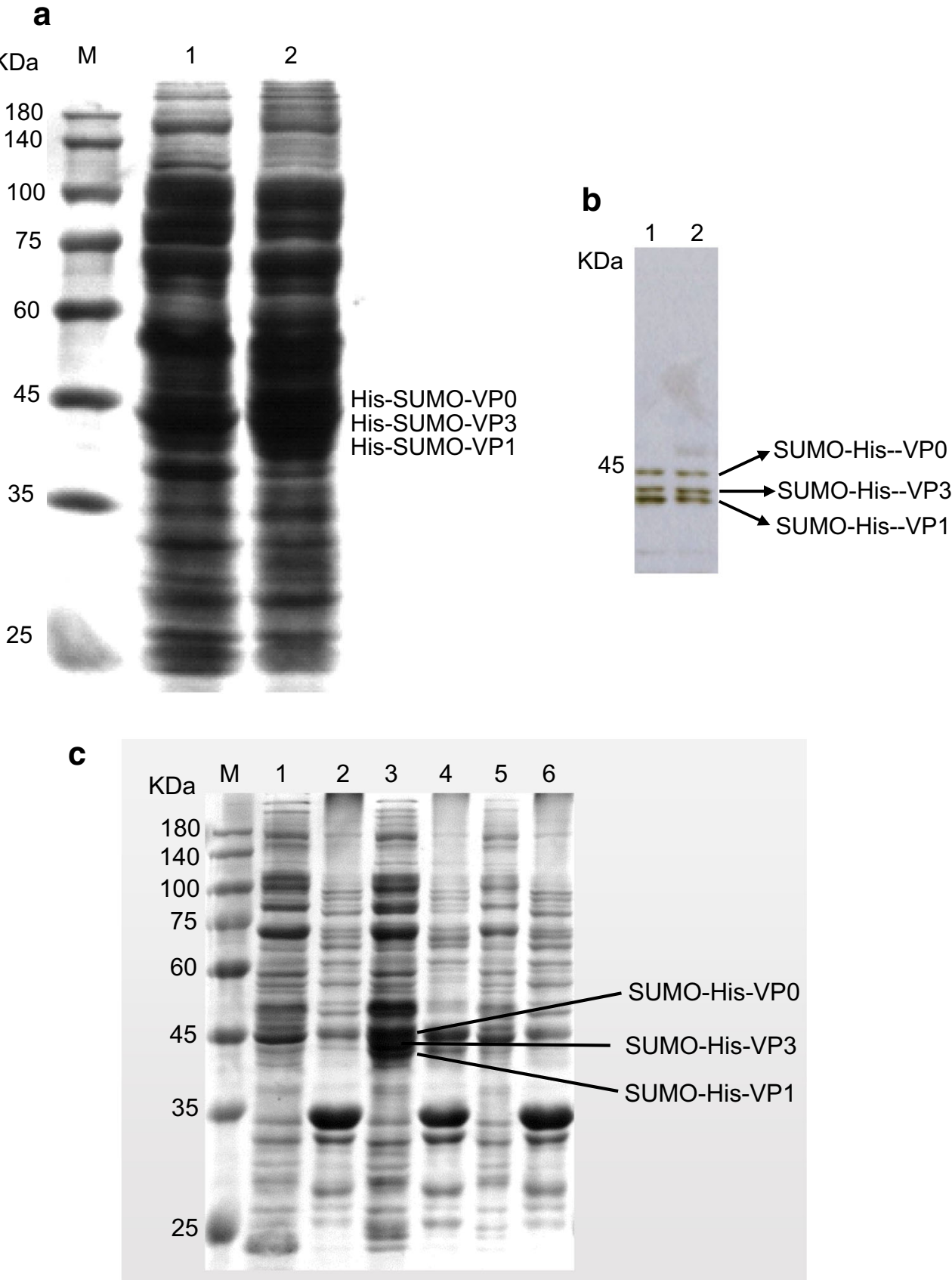
were confirmed to be highly expressed in a soluble manner, and the fusion proteins reacted with the hyperimmune sera against serotype O FMDV (Fig. 1b). Induction at $16{ }^{\circ} \mathrm{C}$ enhanced the yield of soluble recombinant proteins compared with the conditions at $37{ }^{\circ} \mathrm{C}$ (Fig. 1c), and the total yield of the purified fusion proteins reached approximately $18-20 \mathrm{mg}$ per liter of the cell culture at the given induction parameter, and these observations were consistent with previous findings (Guo et al. 2013).

\section{Assembly of FMDV-VLPs}

The SUMO-tag of the purified fusion proteins was removed by treating with SUMO protease, and the VP0-VP1-VP3 ternary protein complex was self-assembled in the same solution system. Then, the protein complex was purified using $\mathrm{Ni}^{+}-$ chelating resin (Guo et al. 2013). The elution was
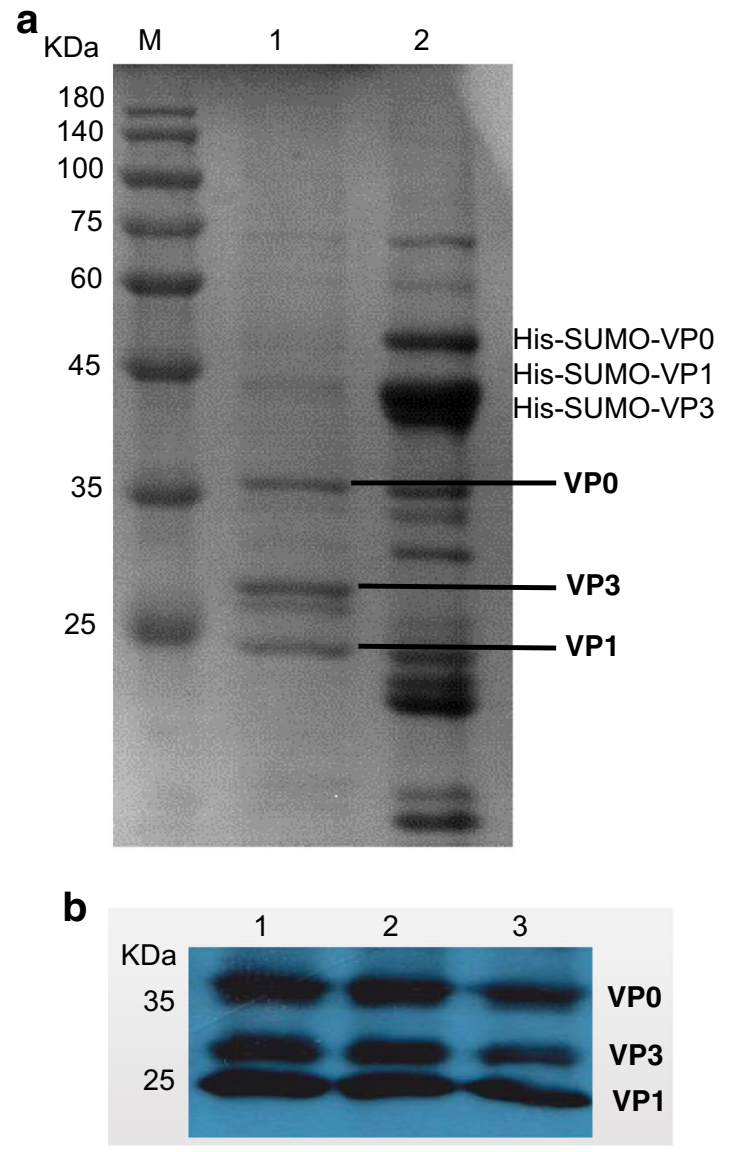

Fig. 2 Expression and assembly of purified FMDV-VLPs (a). Analysis of FMD O serotype virus-like particles using SDS-PAGE. M, protein molecular marker; lane 1, digested recombinant proteins with SUMO protease; lane 2, nondigested recombinant proteins. Analysis of FMD O serotype virus-like particles using western blot (b). Lanes 1-3, purified concentrated and further purified with the sucrose gradient ultracentrifuge. The obtained VLPs were further confirmed through SDS-PAGE (Fig. 2a) and western blot (Fig. 2b). The assembly of FMDV-VLPs based on the VP0-VP1-VP3 ternary protein complex was examined using a transmission electron microscope (TEM). In Fig. 2c, the VP0-VP1-VP3 complex formed round VLP aggregates with a diameter of about $25 \mathrm{~nm}$, which was similar to the size of authentic FMDV particles (Fig. 2d).

\section{Preparation of HRP-conjugated hyperimmune sera in rabbits}

Rabbits were immunized three times in 2-week intervals with $200 \mu \mathrm{g}$ of the purified VLPs emulsified with Freud's adjuvant to generate a competitive antibody with each test serum for the construction of cELISA. The rabbit sera were isolated and
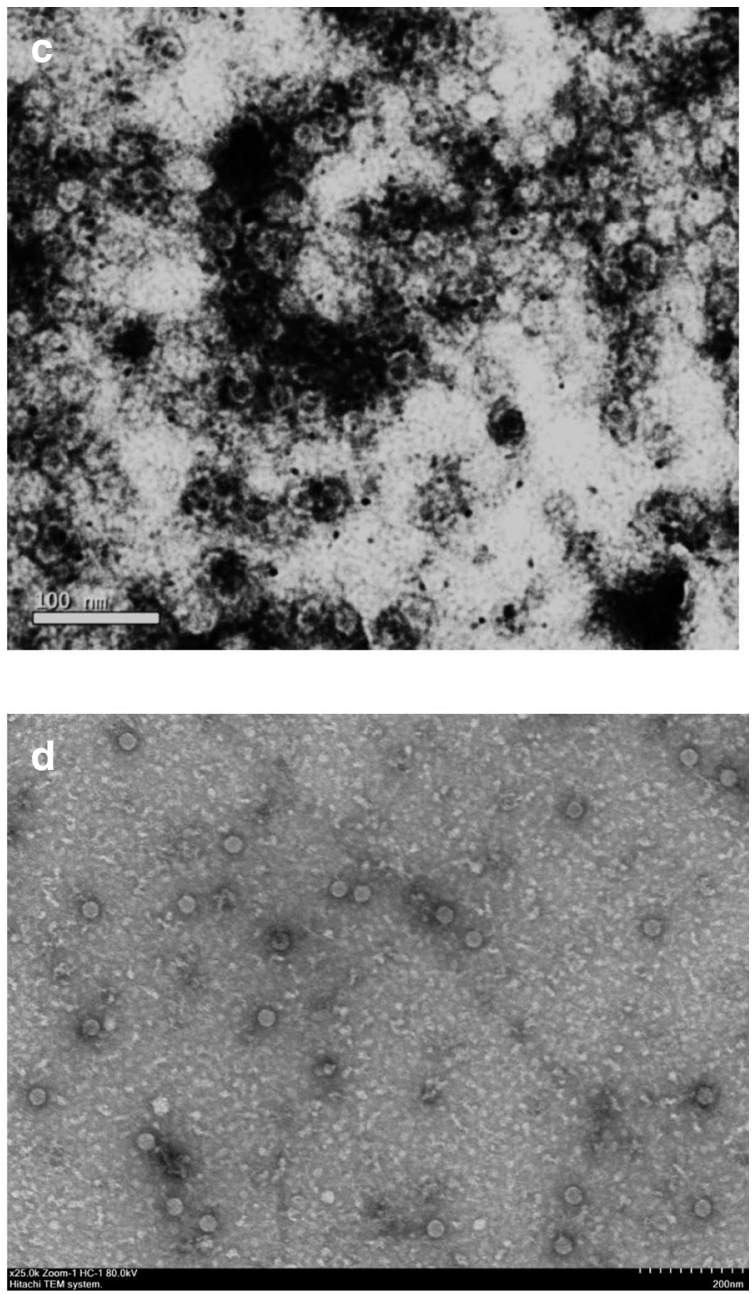

FMD-VLPs generated in varied preparations. Visualization of FMD O serotype virus-like particles using TEM (c). The bar indicates $100 \mathrm{~nm}$. Visualization of FMDV O serotype using TEM (d). The ruler represents $200 \mathrm{~nm}$ 
purified, and IgG was conjugated with horseradish peroxidase. The HRP-conjugated IgG was characterized through western blot and direct ELISA before it was used in cELISA (data not shown).

\section{Development of cELISA based on FMD-VLPs}

The reaction parameters and components were optimized on the basis of the maximum N/P ratio or PI, including the concentration of the coating VLPs and HRP-IgG, incubation time, and temperature, the selection of blocking buffers, serum and HRP-IgG time and temperature, and substrate incubation time and temperature, to obtain the best performance of cELISA with purified VLPs and HRP-conjugated rabbit IgG. The optimal conditions of cELISA were set as follows: $0.5 \mu \mathrm{g} / \mathrm{ml}$ of VLPs in $100 \mu \mathrm{l}$ volume (carbonate solution) and coating at either $37^{\circ} \mathrm{C}$ for $2.5 \mathrm{~h}$ or $4{ }^{\circ} \mathrm{C}$ overnight; blocked with $1 \%$ BSA at $37^{\circ} \mathrm{C}$ for $30 \mathrm{~min}$; competitive reaction at $37^{\circ} \mathrm{C}$ for $30 \mathrm{~min}$ between 1:4 dilution of the tested serum samples and 1:18,000 dilution of HRP-IgG; visualization with TMB substrate at $37^{\circ} \mathrm{C}$ for $10 \mathrm{~min}$; and reaction termination with the addition of $50 \mu \mathrm{l}$ of $2 \mathrm{M} \mathrm{H}_{2} \mathrm{SO}_{4}$.

\section{Determination of the cutoff PI}

A total of the confirmed 50 positive sera and 52 negative sera were examined using the cELISA According to ROC analysis based on data of the cELISA and LPB-ELISA results (Fig. 3a). The value of sensitivity plus specificity was optimal when the cutoff value for the competitive ELISA was set ranging between $40 \%$ and $54.5 \%$ (Fig. 3b). Furthermore, the value of sensitivity plus specificity and the coincidence rate with the identified serum samples were maximal when the cutoff value was set as $50 \%$. Therefore, the cutoff value of PI was set as $50 \%$. Thus, samples with PI of $<50 \%$ were considered negative, and those with PI of $\geq 50 \%$ were considered positive.

\section{Performance evaluation of cELISA}

A total of 277 serum samples were tested and evaluated in comparison with a VDPro ${ }^{\circledR}$ FMDV Type O ELISA kit and a PrioCHECK $®$ FMDV type $\mathrm{O}$ antibody test kit to evaluate the performance of cELISA. The specificity of cELISA was $100 \%$, and the sensitivities reached $96 \%$ based on the
Fig. 3 Validation of cELISA by ROC curve (a). The PI values of 102 confirmed sera calculated by cELISA were compared with the LPB-ELISA results via ROC analysis. AUC stands for area under curve. The value of sensitivity or specificity of the cELISA calculated at varied cutoff value (b)

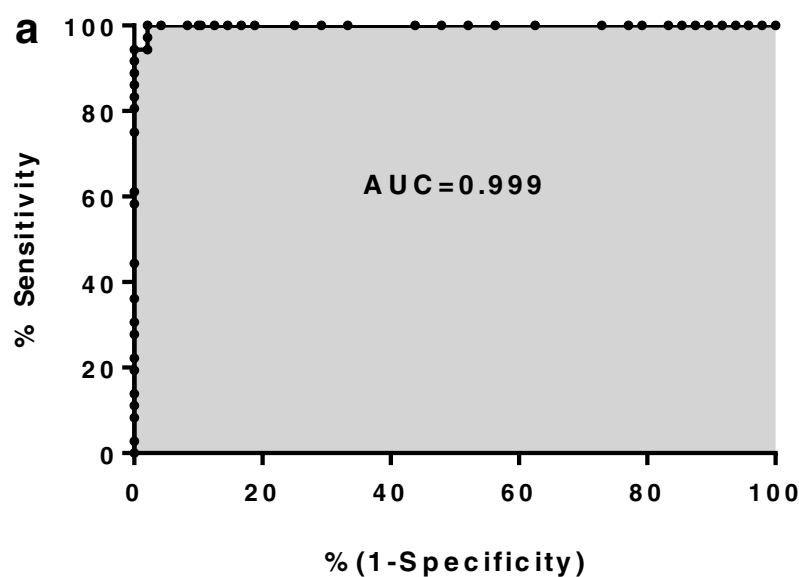

b

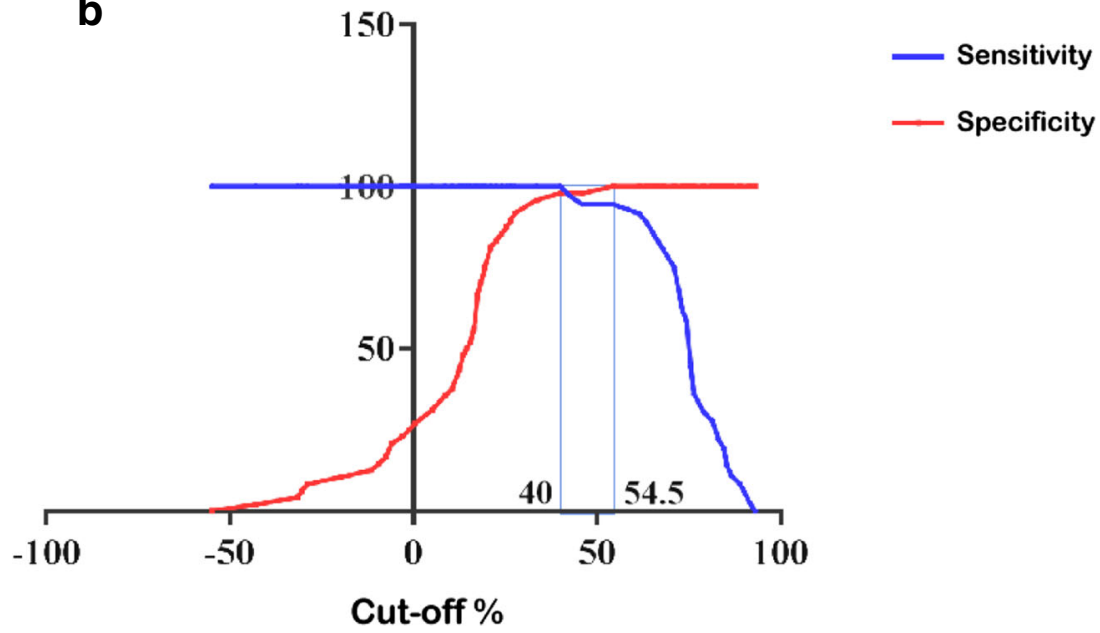


determined cutoff PI in the selected clinical samples, which were confirmed to be strongly positive, weakly positive, or negative through LPB-ELISA. The coincidence rates tested by cELISA compared with the two commercial competitive ELISA kits are shown in Table 1. The coincidence rates of cELISA with a VDPro® FMDV Type O ELISA kit and a PrioCHECK $®$ FMDV type O antibody test kit were $97.8 \%$ and $98.2 \%$, respectively. The reproducibility of cELISA was determined by calculating the PI of each selected clinical sample. In Tables 2 and 3, the intra-assay CV\% of six serum samples ranged from 1.61 to 6.53 , whereas the inter-assay CV\% of these samples was between 1.21 and 13.60. The coefficients of variation of intra- and inter-batch reproducibility tests of the method were less than $15 \%$. The purified FMDVLPs with varied batches were tested as a coating antigen of cELISA, the CV\% with and runs were less than 7.0 and 15.0, respectively, demonstrating high reproducibility and low $\mathrm{CV}$ (Jaworski et al. 2011).

\section{Discussion}

In a previous study, the immunogenicity of the bacterially original FMD-VLPs was evaluated in guinea pigs, swine, and cattle, demonstrating a potential of vaccine candidate (Guo et al. 2013). Such FMD-VLP vaccine candidate is demonstrated to be easy to manufacture, by which cell culture and biocontainment facility are not required. However, herd immunity conferred by the FMD-VLP vaccine should be evaluated for the determination of a vaccination protocol. The FMD-VLP vaccine in combination with an alternative evaluation test will contribute to the prevention and control of FMD, especially in undeveloped countries. Given that immunogenicity of FMD-VLPs have been demonstrated by our previous study and other studies (Guo et al. 2013; Li et al. 2011, 2016), however, the reactogenicity of FMD-VLPs as a coating antigen for the development of cELISA remains unknown. Therefore, a competition ELISA based on bacterially original FMD-VLPs was developed, demonstrating high

Table 1 Comparison of the competitive ELISA with commercial kit for VDPro ${ }^{\circledR}$ FMDV Type O ELISA Kit and PrioCHECKC® FMDV type O antibody test Kit

\begin{tabular}{|c|c|c|c|c|c|}
\hline & & \multicolumn{2}{|l|}{ cELISA } & \multirow{2}{*}{$\begin{array}{l}\text { VDPro® } \\
\text { Total }\end{array}$} & \multirow{2}{*}{$\begin{array}{l}\text { PrioCHECK® } \\
\text { Total }\end{array}$} \\
\hline & & Positive & Negative & & \\
\hline \multirow[t]{2}{*}{ VDPro® } & Positive & 110 & 0 & 110 & \\
\hline & Negative & 6 & 161 & 167 & \\
\hline \multirow[t]{2}{*}{ PrioCHECK® } & Positive & 116 & 5 & & 121 \\
\hline & Negative & 0 & 156 & & 156 \\
\hline cELISA & Total & 116 & 161 & 277 & 277 \\
\hline
\end{tabular}

Table 2 Intra-batch reproducibility test of VLPs-cELISA

\begin{tabular}{lrrrrrr}
\hline Sample ID. & \multicolumn{1}{c}{$1^{\mathrm{d}}$} & \multicolumn{1}{c}{2} & 3 & $X^{\mathrm{c}}$ & $\mathrm{SD}^{\mathrm{b}}$ & $\mathrm{CV}{ }^{\mathrm{a}}$ \\
\hline$\# 1$ & 101 & 103 & 99 & 101 & 1.633 & 1.615 \\
$\# 2$ & 69 & 72 & 74 & 71.7 & 2.04 & 2.846 \\
$\# 3$ & 55 & 56 & 59 & 56.7 & 1.7 & 2.998 \\
$\# 4$ & 33 & 30 & 33 & 32 & 1.141 & 4.419 \\
$\# 5$ & 33 & 35 & 33 & 33.7 & 0.943 & 2.799 \\
$\# 6$ & 23 & 25 & 27 & 25 & 1.633 & 6.532 \\
\hline
\end{tabular}

${ }^{\text {a }}$ Coefficient of variation

${ }^{\mathrm{b}}$ Standard deviation

${ }^{\mathrm{c}}$ Mean PI value

${ }^{\mathrm{d}}$ PI value

specificity, sensitivity, and reproducibility by testing panels of serum samples confirmed using prescribed methods recommended by OIE (OIE 2017).

In this study, the FMD-VLPs with serotype O specificity were constructed by a bacterial system in which the three recombinant expression plasmids harboring VP0, VP1, and VP3 ORF were cotransformed into host cells, induced, and self-assembled. Three gene fragments may be prepared through chemical synthesis rather than through RT-PCR based on the RNA extract of the amplified FMDV in susceptible cells. Hyperimmune sera could be generated through vaccination in animals by using recombinant proteins. Therefore, the essential components for diagnostic tests, including diagnostic antigens and related reference sera, can be generated independently depending on the availability of a high-level biosafety facility, which contributes to the production of antigens associated with highly pathogenic agents, such as FMDV, and its further application in diagnosis or vaccine development (Diaz-San Segundo et al. 2017). Otherwise, the development of diagnostic tests based on killed FMDV depends exclusively on a sophisticated biosafety facility, resulting in high cost and high price. For example, a PrioCHECK ${ }^{\circledR}$ FMDV type $\mathrm{O}$ antibody ELISA kit (Prionics, Swiss) was developed on the basis

Table 3 Inter-batch reproducibility test of VLPs-ELISA

\begin{tabular}{|c|c|c|c|c|c|c|}
\hline Sample ID & $1^{\mathrm{d}}$ & 2 & 3 & $X^{\mathrm{c}}$ & $\mathrm{SD}^{\mathrm{b}}$ & $\mathrm{CV} \%{ }^{\mathrm{a}}$ \\
\hline$\# 1$ & 87 & 97 & 98 & 94 & 4.966 & 5.284 \\
\hline$\# 2$ & 79 & 77 & 77 & 77.7 & 0.943 & 1.214 \\
\hline \# 3 & 60 & 79 & 70 & 69.7 & 7.76 & 11.134 \\
\hline$\# 4$ & 9 & 12 & 10 & 10.3 & 1.248 & 12.113 \\
\hline$\# 5$ & 34 & 28 & 31 & 31 & 2.449 & 7.9 \\
\hline \# 6 & 7 & 5 & 6 & 6 & 0.816 & 13.608 \\
\hline
\end{tabular}


of killed FMDV and monoclonal antibody for competition with antibodies from the test sera, which cost approximately $\$ 1500.00$ for 450 tests and thus unaffordable for clinical use, especially in undeveloped countries. Therefore, we generated FMD-VLPs with type O specificity in a bacterial system, which is believed to be cost efficient and easily prepared in any laboratory with basic equipment for bacterial culture. Thus, FMDV-VLPs generated in this study had a high potential of substitution for inactivated FMDV in the ELISA tests, indicating that cELISA could be applied to assess herd immunization in clinical use, especially in developing countries. The generation of FMD-VLPs with six additional serotypes can be accomplished on the basis of our study, suggesting that cELISA can be applied to examine the level of antibodies triggered by other serotype FMD vaccines.

For the DIVA test, numerous competitive ELISA tests, which are dependent on monoclonal antibodies (mAbs) against FMDV nonstructural proteins, such as $3 \mathrm{ABC}$ and 3B (Lu et al. 2007; Sharma et al. 2012; Yang et al. 2015), have been extensively exploited. These tests demonstrated that the diagnostic specificity and sensitivity were variable, ranging from $84 \%$ to $99.7 \%$. In some circumstances, different mAbs should be combined to obtain the best performance in the ELISA test and overcome the weak affinity of antibodies with coating antigens, though a mAb may show high specificity, sensitivity, and consistent performance (Yang et al. 2016). In this study, the polyclonal antibodies were used as competitive antibodies to assess the levels of herd immunity. In comparison with $\mathrm{mAbs}$, polyclonal antibodies may exhibit stronger affinity by recognizing various epitopes on coating antigens, which represented high specificity and good performance.

FMDV is highly prone to mutation because of the errorprone transcription of RNA-dependent RNA polymerase or the high likeliness of RNA recombination during viral replication (Domingo et al. 2003). Animal herds vaccinated with killed FMDV vaccines create a relevant antibody pressure on viral invasion or spread, which also accelerates the frequency of FMDV to escape from immune protection by host animals (Abubakar et al. 2018). Thus, FMDV exhibits a high degree of genetic variability, resulting in the appearance of seven immunological serotypes and multiple topotypes. For the formation of FMD capsids, VP1 is exposed on the surface of a viral capsid and implicated in capsid stability (Han et al. 2015). VP1 carries the major viral neutralizing antigenic sites, which are the most important targets for diagnostic tests and vaccine development. However, VP1 exhibits a high degree of mutagenesis during viral replication in vitro or in vivo, especially replication in vivo when a high level of neutralizing antibodies exists in host animals (Subramaniam et al. 2017; Alam et al. 2013). Therefore, the frequent update of vaccine strains for vaccine manufacturing is an effective measure for the success of a vaccination campaign (de Los Santos et al. 2018; Mahapatra et al. 2015).
Thus, our FMDV-VLPs generated in this study for the assessment of herd immunization may be required to be updated in agreement with vaccine strains to guarantee the highest sensitivity and best performance or in combination with comprehensively epidemiological surveillance.

In conclusion, cELISA based on bacterially original FMDVLPs established in this study represented high specificity, sensitivity, and reproducibility for the evaluation of herd immunization by commercially available FMD-inactivated vaccines. Our study also applied to the generation of cELISAs for six other serotypes of clinically important FMDV. cELISAbased bacterial FMD-VLPs were easily produced without requiring a high-level biosafety facility and performance with low cost, especially in developing countries, demonstrating that the assay, in combination with comprehensive strategies appropriate for the economic or social conditions in a national context, may contribute to the evaluation of herd immunization with various inactivated FMD vaccines and facilitate the prevention and control of such highly contagious and devastating viral diseases.

Author contributions $\mathrm{XR}$ contributed to the preparation of the manuscript. ZY, HG, and MB designed this analysis. ZY conducted the experiment. XR, XW, and ZY reviewed records. $\mathrm{ZY}, \mathrm{XR}, \mathrm{HG}$, and $\mathrm{SS}$ analyzed the data. ZY and SS prepared the materials. All authors reviewed the manuscript and approved the final manuscript.

Funding This study was supported by the grants "the National Key Research and Development Program of China (2017YFD0501100, 2016YFD05007000)" and the Graduate student innovation fund of Heilongjiang Bayi Agricultural University (YJSCX2017-Y43).

\section{Compliance with ethical standards}

Conflict of interest The authors declare that they have no conflict of interest.

Ethical approval All of the animal experiments were conducted in accordance with the regulations for the administration of affairs concerning experimental animals approved by the State Science and Technology Commission of the People's Republic of China.

Publisher's note Springer Nature remains neutral with regard to jurisdictional claims in published maps and institutional affiliations.

\section{References}

Abubakar M, Manzoor S, Ahmed A (2018) Interplay of foot and mouth disease virus with cell-mediated and humoral immunity of host. Rev Med Virol 28(2). https://doi.org/10.1002/rmv.1966

Alam SM, Amin R, Rahman MZ, Hossain MA, Sultana M (2013) Antigenic heterogeneity of capsid protein VP1 in foot-and-mouth disease virus (FMDV) serotype Asia 1. Adv Appl Bioinform Chem 6:37-46. https://doi.org/10.2147/AABC.S49587

Basagoudanavar SH, Hosamani M, Tamil Selvan RP, Sreenivasa BP, Saravanan P, Chandrasekhar Sagar BK, Venkataramanan R (2013) Development of a liquid-phase blocking ELISA based on foot-and- 
mouth disease virus empty capsid antigen for seromonitoring vaccinated animals. Arch Virol 158(5):993-1001. https://doi.org/10. 1007/s00705-012-1567-5

Chen TH, Lee F, Lin YL, Dekker A, Chung WB, Pan CH, Jong MH, Huang CC, Lee MC, Tsai HJ (2011) Differentiation of foot-andmouth disease-infected pigs from vaccinated pigs using antibodydetecting sandwich ELISA. J Vet Med Sci 73(8):977-984

Chenard G, Miedema K, Moonen P, Schrijver RS, Dekker A (2003) A solid-phase blocking ELISA for detection of type $\mathrm{O}$ foot-and-mouth disease virus antibodies suitable for mass serology. J Virol Methods 107(1):89-98

Chung CJ, Clavijo A, Bounpheng MA, Uddowla S, Sayed A, Dancho B, Olesen IC, Pacheco J, Kamicker BJ, Brake DA, BandaranayakaMudiyanselage CL, Lee SS, Rai DK, Rieder E (2018) An improved, rapid competitive ELISA using a novel conserved 3B epitope for the detection of serum antibodies to foot-and-mouth disease virus. J Vet Diagn Investig 1040638718779641:699-707. https://doi.org/10. $1177 / 1040638718779641$

de Los Santos T, Diaz-San Segundo F, Rodriguez LL (2018) The need for improved vaccines against foot-and-mouth disease. Curr Opin Virol 29:16-25. https://doi.org/10.1016/j.coviro.2018.02.005

Diaz-San Segundo F, Medina GN, Stenfeldt C, Arzt J, de Los Santos T (2017) Foot-and-mouth disease vaccines. Vet Microbiol 206:102112. https://doi.org/10.1016/j.vetmic.2016.12.018

Ding YZ, Chen HT, Zhang J, Zhou JH, Ma LN, Zhang L, Gu Y, Liu YS (2013) An overview of control strategy and diagnostic technology for foot-and-mouth disease in China. Virol J 10:78. https://doi.org/ 10.1186/1743-422X-10-78

Domingo E, Escarmis C, Baranowski E, Ruiz-Jarabo CM, Carrillo E, Nunez JI, Sobrino F (2003) Evolution of foot-and-mouth disease virus. Virus Res 91(1):47-63

Feng X, Ma JW, Sun SQ, Guo HC, Yang YM, Jin Y, Zhou GQ, He JJ, Guo JH, Qi SY, Lin M, Cai H, Liu XT (2016) Quantitative detection of the foot-and-mouth disease virus serotype O $146 \mathrm{~S}$ antigen for vaccine production using a double-antibody sandwich ELISA and nonlinear standard curves. PLoS One 11(3):e0149569. https://doi. org/10.1371/journal.pone.0149569

Ferris NP, Kitching RP, Oxtoby JM, Philpot RM, Rendle R (1990) Use of inactivated foot-and-mouth disease virus antigen in liquid-phase blocking ELISA. J Virol Methods 29(1):33-41

Fry EE, Stuart DI, Rowlands DJ (2005) The structure of foot-and-mouth disease virus. Curr Top Microbiol Immunol 288:71-101

Gao M, Zhang R, Li M, Li S, Cao Y, Ma B, Wang J (2012) An ELISA based on the repeated foot-and-mouth disease virus 3B epitope peptide can distinguish infected and vaccinated cattle. Appl Microbiol Biotechnol 93(3):1271-1279. https://doi.org/10.1007/s00253-0113815-0

Guo HC, Sun SQ, Jin Y, Yang SL, Wei YQ, Sun DH, Yin SH, Ma JW, Liu ZX, Guo JH, Luo JX, Yin H, Liu XT, Liu DX (2013) Foot-andmouth disease virus-like particles produced by a SUMO fusion protein system in Escherichia coli induce potent protective immune responses in guinea pigs, swine and cattle. Vet Res 44:48. https:// doi.org/10.1186/1297-9716-44-48

Han SC, Guo HC, Sun SQ (2015) Three-dimensional structure of footand-mouth disease virus and its biological functions. Arch Virol 160(1):1-16. https://doi.org/10.1007/s00705-014-2278-x

Hosamani M, Basagoudanavar SH, Tamil Selvan RP, Das V, Ngangom P, Sreenivasa BP, Hegde R, Venkataramanan R (2015) A multi-species indirect ELISA for detection of non-structural protein $3 \mathrm{ABC}$ specific antibodies to foot-and-mouth disease virus. Arch Virol 160(4): 937-944. https://doi.org/10.1007/s00705-015-2339-9

Jaworski JP, Compaired D, Trotta M, Perez M, Trono K, Fondevila N (2011) Validation of an r3AB1-FMDV-NSP ELISA to distinguish between cattle infected and vaccinated with foot-and-mouth disease virus. J Virol Methods 178(1-2):191-200. https://doi.org/10.1016/j. jviromet.2011.09.011
Knight-Jones TJ, Rushton J (2013) The economic impacts of foot and mouth disease - what are they, how big are they and where do they occur? Prev Vet Med 112(3-4):161-173. https://doi.org/10.1016/j. prevetmed.2013.07.013

Ko YJ, Jeoung HY, Lee HS, Chang BS, Hong SM, Heo EJ, Lee KN, Joo HD, Kim SM, Park JH, Kweon CH (2009) A recombinant proteinbased ELISA for detecting antibodies to foot-and-mouth disease virus serotype Asia 1. J Virol Methods 159(1):112-118. https:// doi.org/10.1016/j.jviromet.2009.03.011

Ko YJ, Lee HS, Park JH, Lee KN, Kim SM, Cho IS, Joo HD, Paik SG, Paton DJ, Parida S (2012) Field application of a recombinant protein-based ELISA during the 2010 outbreak of foot-and-mouth disease type A in South Korea. J Virol Methods 179(1):265-268. https://doi.org/10.1016/j.jviromet.2011.09.021

Li Z, Yin X, Yi Y, Li X, Li B, Lan X, Zhang Z, Liu J (2011) FMD subunit vaccine produced using a silkworm-baculovirus expression system: protective efficacy against two type Asial isolates in cattle. Vet Microbiol 149(1-2):99-103. https://doi.org/10.1016/j.vetmic.2010. 10.022

Li H, Li Z, Xie Y, Qin X, Qi X, Sun P, Bai X, Ma Y, Zhang Z (2016) Novel chimeric foot-and-mouth disease virus-like particles harboring serotype O VP1 protect guinea pigs against challenge. Vet Microbiol 183:92-96. https://doi.org/10.1016/j.vetmic.2015.12.004

Lu Z, Cao Y, Guo J, Qi S, Li D, Zhang Q, Ma J, Chang H, Liu Z, Liu X, Xie Q (2007) Development and validation of a 3ABC indirect ELISA for differentiation of foot-and-mouth disease virus infected from vaccinated animals. Vet Microbiol 125(1-2):157-169. https:// doi.org/10.1016/j.vetmic.2007.05.017

Ma LN, Zhang J, Chen HT, Zhou JH, Ding YZ, Liu YS (2011) An overview on ELISA techniques for FMD. Virol J 8:419. https:// doi.org/10.1186/1743-422X-8-419

Mahajan S, Mohapatra JK, Pandey LK, Sharma GK, Pattnaik B (2015) Indirect ELISA using recombinant nonstructural protein 3D to detect foot and mouth disease virus infection associated antibodies. Biologicals 43(1):47-54. https://doi.org/10.1016/j.biologicals. 2014.10.002

Mahapatra M, Yuvaraj S, Madhanmohan M, Subramaniam S, Pattnaik B, Paton DJ, Srinivasan VA, Parida S (2015) Antigenic and genetic comparison of foot-and-mouth disease virus serotype $\mathrm{O}$ Indian vaccine strain, $\mathrm{O} / \mathrm{IND} / \mathrm{R} 2 / 75$ against currently circulating viruses. Vaccine 33(5):693-700. https://doi.org/10.1016/j.vaccine.2014.11.058

Minaeian S, Rahbarizadeh F, Zarkesh Esfahani SH, Ahmadvand D (2012) Characterization and enzyme-conjugation of a specific antiL1 nanobody. J Immunoassay Immunochem 33(4):422-434. https:// doi.org/10.1080/15321819.2012.665407

Oem JK, Park JH, Lee KN, Kim YJ, Kye SJ, Park JY, Song HJ (2007) Characterization of recombinant foot-and-mouth disease virus pentamer-like structures expressed by baculovirus and their use as diagnostic antigens in a blocking ELISA. Vaccine 25(20):41124121. https://doi.org/10.1016/j.vaccine.2006.08.046

OIE, World Organization for Animal Health (2017) Foot and mouth disease (infection with food and mouth disease virus). Chapter 2.1.8. Available online: http://120.52.51.13/www.oie.int/ fileadmin/Home/eng/Health_standards/tahm/2.01.08_FMD.pdf. Accessed Feb 152019

Paiba GA, Anderson J, Paton DJ, Soldan AW, Alexandersen S, Corteyn M, Wilsden G, Hamblin P, MacKay DK, Donaldson AI (2004) Validation of a foot-and-mouth disease antibody screening solidphase competition ELISA (SPCE). J Virol Methods 115(2):145158. https://doi.org/10.1016/j.jviromet.2003.09.016

Porphyre T, Rich KM, Auty HK (2018) Assessing the economic impact of vaccine availability when controlling foot and mouth disease outbreaks. Front Vet Sci 5(47). https://doi.org/10.3389/fvets.2018.00047

Rawdon TG, Garner MG, Sanson RL, Stevenson MA, Cook C, Birch C, Roche SE, Patyk KA, Forde-Folle KN, Dube C, Smylie T, Yu ZD (2018) Evaluating vaccination strategies to control foot-and-mouth 
disease: a country comparison study. Epidemiol Infect 1-13. https:// doi.org/10.1017/S0950268818001243

Roche SE, Garner MG, Sanson RL, Cook C, Birch C, Backer JA, Dube C, Patyk KA, Stevenson MA, Yu ZD, Rawdon TG, Gauntlett F (2015) Evaluating vaccination strategies to control foot-and-mouth disease: a model comparison study. Epidemiol Infect 143(6):12561275. https://doi.org/10.1017/S0950268814001927

Sharma GK, Mohapatra JK, Pandey LK, Mahajan S, Mathapati BS, Sanyal A, Pattnaik B (2012) Immunodiagnosis of foot-and-mouth disease using mutated recombinant $3 \mathrm{ABC}$ polyprotein in a competitive ELISA. J Virol Methods 185(1):52-60. https://doi.org/10. 1016/j.jviromet.2012.05.029

Subramaniam S, Das B, Biswal JK, Ranjan R, Pattnaik B (2017) Antigenic variability of foot-and-mouth disease virus serotype $\mathrm{O}$ during serial cytolytic passage. Virus Genes 53(6):931-934. https://doi.org/10.1007/s11262-017-1494-3

Xiao Y, Chen HY, Wang Y, Yin B, Lv C, Mo X, Yan H, Xuan Y, Huang Y, Pang W, Li X, Yuan YA, Tian K (2016) Large-scale production of foot-and-mouth disease virus (serotype Asia1) VLP vaccine in Escherichia coli and protection potency evaluation in cattle. BMC Biotechnol 16(1):56. https://doi.org/10.1186/s12896-016-0285-6

Yang M, Parida S, Salo T, Hole K, Velazquez-Salinas L, Clavijo A (2015) Development of a competitive enzyme-linked immunosorbent assay for detection of antibodies against the $3 \mathrm{~B}$ protein of foot-and-mouth disease virus. Clin Vaccine Immunol 22(4):389-397. https://doi.org/ 10.1128/CVI.00594-14

Yang M, Xu W, Bittner H, Horsington J, Vosloo W, Goolia M, Lusansky D, Nfon C (2016) Generation of mAbs to foot-and-mouth disease virus serotype A and application in a competitive ELISA for serodiagnosis. Virol J 13(1):195. https://doi.org/10.1186/s12985016-0650-Z

Yin S, Sun S, Yang S, Shang Y, Cai X, Liu X (2010) Self-assembly of virus-like particles of porcine circovirus type 2 capsid protein expressed from Escherichia coli. Virol J 7:166. https://doi.org/10. 1186/1743-422X-7-166 